\title{
Externally Acquired Radiological Image Data and Reporting for the Clinical Routine, Conference and Boards - Legal Aspects of the Second Opinion in Germany
}

\author{
Externe radiologische Aufnahmen und Befunde in der klinischen \\ Routine, Konferenzen und Boards - rechtliche Aspekte der \\ Nachbefundung und Zweitmeinung in Deutschland
}

Authors

Andreas G. Schreyer ${ }^{1}$, Britta Rosenberg ${ }^{2}$, René T. Steinhäuser ${ }^{3}$

Affiliations

1 Department of Radiology, Universitätsklinikum Regensburg, Germany

2 Telemedicine Euroregion Pomerania Project, Department of Diagnostic Radiology and Neuroradiology, Ernst-MoritzArndt-Universität Greifswald, Germany

3 Medical Law, Rechtsanwälte Wigge, Hamburg, Germany

Key words

health policy and practice, socioeconomic issues,

second opinion

received 14.07.2017

accepted 08.01.2018

Bibliography

DOI https://doi.org/10.1055/s-0044-102306

Published online: 7.3.2018

Fortschr Röntgenstr 2018; 190: 610-615

(c) Georg Thieme Verlag KG, Stuttgart · New York

ISSN 1438-9029

Correspondence

Herr Prof. Andreas G. Schreyer

Department of Radiology, University Hospital Regensburg,

Franz-Josef-Strauss-Allee 11,

93053 Regensburg, Germany

Tel.: ++ 49/941/9447442

andreas.schreyer@klinik.uni-regensburg.de

\section{ABSTRACT}

Background Because of an increasing number of boards and conferences, the number of second opinion readings of externally acquired image data is growing dramatically. In this review article we intend to give medical and legal recommendations for the documentation and interpretation of externally acquired radiological data for second opinions and board presentations based on German jurisdiction.

Method Using the FAQ format as a dialog between radiologists and medical legal experts, we answer the most crucial questions regarding correct documentation and interpretation for externally acquired radiological image data based on an up-to-date literature search.

Results Based on the unity of radiological image data and the corresponding written report according to the radiation protection law, the primary report should be present when composing a second opinion. If the primary external report is not present, this should be mentioned as a limitation. All radiological second opinions should be documented in written form. This is especially important in cases of discrepant findings. Legally, the attending physician is responsible for selecting the radiological opinion. The radiologist should not rely on the written primary report without personal reevaluation. Legally, it would be considered radiological malpractice if the external image data and previous image data are not evaluated personally.

Conclusion From a legal point of view, there are explicit recommendations regarding thorough documentation of a second opinion as an independent medical service in all cases.

\section{Key Points}

- The written external report should be present when composing a second opinion report or case presentation.

- Second opinions or external case interpretations should be documented in written form.

- It is considered malpractice to completely rely on the external written report for a second opinion.

- In discrepant radiological findings the treating physician is responsible for choosing the correct radiological interpretation.

\section{Citation Format}

- Schreyer AG, Rosenberg B, Steinhäuser RT. Externally Acquired Radiological Image Data and Reporting for the Clinical Routine, Conference and Boards - Legal Aspects of the Second Opinion in Germany. Fortschr Röntgenstr 2018; 190: 610-615

\section{ZUSAMMENFASSUNC}

Hintergrund Durch die Zunahme von Boards und Konferenzen nimmt die Zahl an Nachbefundungen im Sinne von Zweit- 
meinungen oder Röntgendemonstrationen extern erstellter Aufnahmen beträchtlich zu. In diesem Übersichtsartikel sollen juristisch und medizinisch Empfehlungen zur Dokumentation und Interpretation extern erstellter Aufnahmen hinsichtlich Zweitmeinung und Demonstration in Boards basierend auf der deutschen Rechtsprechung erfolgen.

Methode Im FAQ-Format als Dialog zwischen Radiologen und medizinisch spezialisierten Juristen werden die wichtigsten Fragen bezüglich korrekter Dokumentation und Interpretation externer Bilddaten basierend auf aktueller Literatur beantwortet.

Ergebnisse Entsprechend der strahlenschutzrechtlichen Einheit von Bild und Befund sollte der primäre Befund zur Durchführung einer Zweitmeinung vorliegen. Fehlende externe
Befunde sollten als Einschränkung erwähnt werden. Generell soll eine radiologische Zweitmeinung schriftlich dokumentiert werden. Dies ist besonders bei widersprüchlichen Aussage zum Primärbefund wichtig. Es bleibt jedoch in der Entscheidung des behandelnden Arztes, welche radiologische Meinung er für korrekt erachtet. Bei Zweitmeinungen darf sich nicht ungeprüft auf externe Befunde verlassen werden. Die Sorgfaltspflicht fordert hier eine eigene fachliche Einschätzung des Bildmaterials inkl. der Voruntersuchungen.

Schlussfolgerung Vom juristischen Standpunkt bestehen klare Empfehlungen, die prinzipiell eine sorgfältige Dokumentation einer Zweitbefundung im Sinne einer eigenverantwortlichen ärztlichen Leistung in allen Fällen fordern.

\section{Introduction}

Participation in interdisciplinary tumor boards and radiology case conferences has become an essential part of clinical radiology. These interdisciplinary case conferences and boards make recommendations regarding optimal treatment regimes. Therefore, they make decisions with far-reaching consequences. The correct presentation and interpretation of radiological images in this setting is extremely important.

Patients with at least some externally acquired radiological images are often presented with the presenting radiologist not being involved in the primary examination and reporting. As a result of the digitalization of radiology allowing the transmission of image data via networks and optical media, the number of externally acquired images at clinical radiology facilities has increased significantly. Ideally the written report by the primary radiologist performing the examination is provided with externally acquired images. However, this is often not the case. In addition, radiologists are often asked to spontaneously present externally acquired images without sufficient preparation time in tumor boards and radiology case conferences. Therefore, complete and correct interpretation of externally acquired images of complex diseases must be performed quickly under time pressure without knowledge of the clinical data, the indication, the technical parameters and the type of contrast agent application of the externally performed examination since this information is often not provided with the image data.

The demand for radiology second opinions is also increasing in light of the quick and high availability of digitized image data and the increasingly high level of subspecialization in radiology. It was able to be shown in studies that second opinions provide significant additional information and often result in a change in diagnosis and treatment, especially in highly specialized areas such as neuroradiology and pediatric radiology [1 - 3].

In the context of the presentation of externally acquired images in clinical rounds and tumor boards or as part of a second opinion and the generation of supplementary written reports, there is significant uncertainty among radiologists regarding the legal requirements for implementation and documentation. This uncertainty is further complicated by superficial legal knowledge regarding this topic. Therefore, there is currently a lack of consensus in radiology regarding the extent to which external reports and second opinions must be documented in writing and in the RIS (radiology information system). It is also unclear whether the externally written report is legally required and which radiological finding is legally valid in the case of deviating opinions.

In an attempt to clarify this topic that is both common and full of uncertainty in the radiological routine, we created a medicolegal dialog regarding the most common radiological questions. The "FAQ" format was selected in order to ensure clarity and readability. Questions arising from the clinical routine in radiology are answered and discussed by lawyers specialized in health law.

The complex current reimbursement situation and the creation of second opinions and the presentation of externally acquired images in boards and radiology case conferences are to be discussed in relation to the E-Health law in a subsequent article.

\section{Radiological interpretation of externally acquired images}

Digital externally acquired images from external radiology clinics and practices are often presented in tumor boards and radiology case conferences. However, the corresponding external written reports are often not available. In addition, usually only insufficient labeling of radiological image data regarding contrast agent, contrast agent phases, and examination techniques is available. The images are often generated by units with different sequence names and properties as is often the case in MRI examinations performed on units from different manufacturers. The presenting radiologist is also not able to talk to the patient and does not have access to a detailed medical history. In some cases the radiological images must be presented in a tumor board or a clinical conference ad hoc without any clinical information or with only short and insufficient preparation time. However, the statements made by the radiologist performing the second interpretation in the case conference or tumor board have a significant effect on treatment. As a result, decisions regarding surgical interventions, 
chemotherapy, and treatment stratification in palliative or curative treatment are often made based on ad hoc recommendations by the radiologist. There is the belief among radiologists that an image is linked to the primary finding of the external radiologist, i. e., the primary report is legally binding and valid. This coincides with the principle of the unity of images and the corresponding report according to the radiation protection law.

\section{Radiology question: Ad hoc interpretation of exter- nally acquired images without access to the primary report in radiology case conferences and boards}

I am asked to present and evaluate externally acquired, complex radiological images (CT, MRI, angiography). The primary externally generated report is not available. Is it acceptable to present and evaluate these externally acquired images without the external primary reports, i. e., with limited knowledge of the medical history, exact problem, examination method and technique in the absence of the time pressure of an emergency situation? Or should I deny the request in this elective situation and demand to first see the external written report? Do I perhaps even need a verbal or written disclaimer regarding the tentativeness and possible inaccuracy of my ad hoc evaluation, since I am being asked to make a statement without sufficient preparation time?

\section{Legal response:}

You are solely responsible for your diagnostic work. You should explicitly note any deficiencies in your work to be attributed to the unknown examination circumstances and the lack of availability of the primary report in your documentation. If in your professional opinion additional sequences are required, you must explicitly state this and request that they be acquired. Your documentation should include a note stating that you did not have access to the primary report and knowledge of the examination circumstances of the externally acquired images. It is recommended to wait for the primary report as long as such a delay is medically acceptable. It is highly recommended to take this into consideration in your own report.

\section{Radiology question: Is there a documentation requirement for external reports?}

If I present and evaluate externally acquired radiological images without the external report, to what extent must I document my statements in writing since my statements can have surgical and therapeutic consequences?

\section{Legal response:}

You bear full responsibility for any diagnostic service that you render. These services are to be rendered according to current scientific knowledge and experience. Documentation is to be performed in writing as for all diagnostic reporting.

\section{Joint legal and radiological comment:}

In the daily routine at a large hospital, this legally required documentation can present major practical challenges. The high number of daily requests to put external image material into a relevant clinical context for therapeutic decisions together with the requirement for systematic written documentation results in a workload in radiology that is hardly economically possible. As a realistic solution to this issue in the daily routine, all verbal statements made by the radiologist in radiology case conferences and tumor boards that are decisive for treatment should be documented in some form in writing. In the case of tumor boards, this requirement should be sufficiently met by the synopses of the most important statements and decisions regarding a patient that are saved in the HIS. In the case of non-critical statements made by the presenting radiologist in radiology case conferences that are identical to those in the primary radiology report, there should not be any potential legal conflict.

\section{Radiology question: Validity of my own vs. an external radiological opinion - what counts?}

If I have access to an externally acquired image with the external report and I have a different interpretation than the primary radiologist, i. e., the radiologist who acquired the image, which finding is legally valid? To what extent do I need to document my divergent opinion? In which form should I document my finding?

\section{Legal response:}

This corresponds to a second opinion. Since this situation involves equivalent services by at least two radiologists, you are required to fully examine the available external images and the external report on the basis of your professional expertise. Therefore, your finding is valid for you. Your divergent finding indicates that you do not agree with the initial finding. An external report is only given priority if it is from a different area of specialization than yours and there is no direct overlap between the two areas. Therefore, you are required to review radiological images acquired by an orthopedist, while you typically cannot review the findings of a pathologist. However, you should never ignore discrepancies. You must report anything that would be evident even to a layman, e. g. obviously incorrect assignment of a tissue sample to a patient. The treating physician must then decide which finding is valid. Documentation is made in writing and electronically. If a patient is not to be stored in the RIS (radiology information system), document the event and your finding at least in writing and keep this written documentation for ten years as legally stipulated. Be sure to observe the hospital's own rules regarding documentation or ask your hospital's legal department whether the hospital has its own rules, which can also be defined by the liability insurance company.

\section{Radiology question: Is documentation necessary in the case of a divergent opinion?}

A radiologist presents externally acquired images in a radiology case conference or tumor board and has an opinion that differs from the external primary report. The radiologist is asked to record his divergent opinion in writing. Which report is legally valid? Should the divergent second opinion even be documented in writing, especially since limited information regarding medical history and examination method is available in the primary data? 


\section{Legal response:}

Complete documentation is always necessary. This includes reference to the fact that certain documents were not available and could not be acquired (if applicable). Documentation is particularly relevant in practice in the case of divergent findings. The conflict begins even before the start of treatment, resulting in a particular risk of complications. However, ultimately no report counts more: The treating physician makes treatment decisions and bears responsibility for care in such a situation. The physician must decide whether to follow the preliminary report with presumably complete documentation and images or a second report based on incomplete information. Therefore, it may be advantageous for the treating physician to perform additional examinations to eliminate any remaining doubts.

The legal requirements regarding the liability of a tumor board or future teams in outpatient, specialized care according to $\S 116 \mathrm{~b}$ of the German Code of Social Law (SGB) $V$ has not yet been defined. A tumor board is currently allowed to give a treatment recommendation only when it is professionally sound and relates to the concrete individual medical case. The treating physician is responsible for deciding whether to follow the multidisciplinary recommendation of the tumor board or to deviate from it. In the event of a subsequent liability case, the treating physician can refer to the combined expertise of the tumor board. A courtappointed expert would have to include all considerations from the tumor board in his expert opinion and deem the decision to be not medically acceptable in order to reject the treatment decision made by the treating physician. In contrast, a treating physician who did not follow the recommendation of the tumor board must be able to show in the case of such legal proceedings with medical justification that the deviation from the recommendation or lack of implementation of the recommendation was medically acceptable or was even necessary. In this respect, this is similar to the use of guidelines, which are abstract by nature and thus deviate from the concrete recommendations of a tumor board. However, it is more likely for it to be recommended or even necessary to deviate from a guideline for medical reasons in an individual case than from a recommendation of a tumor board - provided that the physicians participating in the tumor board have the same knowledge as the treating physician.

\section{Radiology question: Is it possible to rely on externally written radiology reports?}

Externally acquired radiological images with a written report by the primary radiologist are available. Can I rely on the information presented in the primary external report for my presentation or am I, as a radiologist, obligated to review the complete examination including all of the potentially numerous images to form my own independent opinion?

\section{Legal response:}

Tumor boards must be organized so that the structures and expertise ensure adequate advisory activity of the represented areas of specialization. Tumor board participants do not automatically become co-treating physicians according to $§ 630$ a of the
German Civil Code (BGB) as a result of participation in the tumor board but they are subject to the duty of care of a consulting physician. Tumor board decisions are considered recommendations, i. e., they are not legally binding and do not excuse the treating physician from the duty of critically reviewing the recommendations prior to implementation. On the other hand, the treating physician must be able to justify non-compliance with tumor board decisions on the basis of medical duty of care. The requirements for the documentation of tumor boards are the same as for every other consulting activity [4]. There is a relationship of confidentiality between the referring physician and the co-treating consulting physician or a consulting physician consulted solely for diagnostic purposes. Therefore, the physician providing further care can rely on the correctness of a report from a consulted physician from another area of specialization and need only pursue that which is unclear or grave concerns or doubts based on the standard of the relevant area of specialization (see medical liability case law of the federal high court 0920/24; federal high court case law, German Civil Code $\S 823$ paragraph 1 medical liability 26 and the Palatine Higher Regional Court in Zweibrücken, decision dated November 3, 1998 - 5 U 56/97 - margin no. 70, juris). Conversely, the consulting physician cannot simply rely on the evaluation of a colleague of the same area of specialization. An independent evaluation of provided radiological images is therefore part of the duty of care of the radiologist participating in the tumor board. Protection of confidence is limited to reporting by a colleague from another area of specialization. Within one's own area of specialization, it is possible and also reasonable for the radiologist to perform an independent professional review of the images.

\section{Evaluation of externally acquired radio- logical images in an emergency setting}

At night and on weekends, on-duty radiology residents or specialists often receive externally acquired radiological images without a written report with the urgent request for an immediate second opinion in an emergency setting. Such opinions often have immediate and at times serious invasive therapeutic consequences, such as emergency surgery.

\section{Radiology question: Interpreting externally acquired images in an emergency setting}

How should external reports in the emergency setting be handled? Who is liable in the case of an interpretation that deviates from the primary report, which is not available in the emergency setting? Is written documentation of verbal statements made in the emergency setting also legally recommended or even mandatory?

\section{Legal response:}

A legal differentiation is made between the time of documentation and the documentation content as well as the form of documentation. §630 f. paragraph 1 sentence 1 of the German Civil Code (BGB) defines this obligation with respect to time. Documentation must be performed in direct temporal connection with 
treatment. With regard to radiologists, treatment means examination. As a rule, a lower standard of care for documentation can be applied in an emergency setting. Treatment of the patient is the main focus while measures that can be delayed, like documentation, are secondary. However, the emergency situation will end eventually. Documentation must be completed at this time at the latest.

Documentation should include everything that is typically documented in a medical context. As a rule, the primary finding and secondary findings should be documented in writing or electronically in the patient file as is common practice in medicine. According to $\S 630 \mathrm{f}$. paragraph 2 of the German Civil Code (BGB), all measures that are medically significant for current and future treatment and the results thereof, in particular medical history, diagnoses, examinations, examination results, findings, treatments/interventions and their effect, and informed consent, are to be recorded in the patient file. Compliance with this definition of documentation, which also corresponds to the code of medical ethics, will fulfill the legal requirements.

\section{Second opinion provided by subspecialized radiologists}

\section{Radiology question: Do the opinions of radiology subspecialists bear more weight?}

Do I need the primary report for second opinions or radiological consultation in special areas such as neuroradiology or pediatric radiology for reference in my written report?

\section{Legal response:}

According to the requirements for specialist training, diagnostic reporting in the areas of neuroradiology and pediatric radiology is allowed in spite of a lack of subspecialization in pediatric radiology and neuroradiology. A subspecialization builds upon specialist training in a certain area of specialization and does not limit the activity of a subspecialized radiologist to that specific area of subspecialization. As a rule, available and known previous findings are to be taken into consideration in one's own diagnostic evaluation of images and the use thereof is to be documented. However, you are legally allowed to review the images without bias in a first step, compare your findings with the previous findings in a second step and then merge the results. If the results are congruent, hardly any explanations are needed while clarification is required in the case of divergent results to avoid a diagnostic error.

\section{Radiology question: Legal assessment of a second opinion requested via teleradiology}

How should radiologists handle data and second opinion requests received via teleradiology that may not be transmitted and evaluated as part of teleradiological evaluation in an emergency setting from a legal standpoint?

\section{Legal response:}

Second opinions are a medical advisory service. It is immaterial whether the images are sent to the radiologist via teleradiology or on a CD or other data medium. As in every case, the images must be inspected to ensure that image quality meets the medical standard. The particular means of transmission can result in qualitative issues requiring documentation. However, this is not particular to teleradiology but rather is a fundamental risk of data transmission since every type of data transmission has certain risks regarding quality.

\section{Summary and discussion of the results}

Tumor boards and interdisciplinary radiology case conferences represent a steadily growing part of the daily routine in clinical radiology. It was able to be shown that interdisciplinary radiology case conferences resulted in a change in diagnosis and treatment in approximately $1 / 3$ of presented cases [5]. Precise numbers regarding the percentage of externally acquired images in radiology case conferences and tumor boards are not available. However, the workload for second opinions for externally acquired images has increased greatly in recent years due to the ubiquitous availability of digital radiological images.

For elective radiology second opinions as well as for the preparation of externally acquired radiological images for tumor boards or radiology case conferences, the external report should be available in writing or electronically in order to ensure that the complete complex medical content can be evaluated in relation to previous images, technical examination methods, and indication for radiological evaluation. As a rule, radiology second opinions must be documented in writing both for consultations as well as presentation in tumor boards or radiology case conferences. The requirement regarding written documentation is met by the recorded minutes of a tumor board. Particularly if a second opinion diverges from the primary report, proper documentation should be provided. When presenting externally acquired images, the radiologist must not blindly rely on the external written report. As part of the duty of care, a presenting radiologist is required to assess externally acquired images including all previous examinations prior to presentation. This has a particular impact on the radiology workload for externally acquired images in the clinical routine since it requires the radiologist providing the second opinion to perform an extensive review of the entire case.

If the external written report is not available for a second opinion or presentation, this limitation due to the lack of detailed information regarding examination method, indication and medical history should be explicitly mentioned and documented.

In the case of a discrepancy between the primary radiology report and the radiology second opinion, the treating managing physician is responsible for deciding which interpretation to follow.

In the case of a request for an ad hoc radiology second opinion in a medical emergency, the standard of care regarding documentation is initially lower as a result of the emergency setting. However, proper documentation of the second opinion should be provided once the emergency situation is over. 


\section{Conflict of Interest}

The authors declare that they have no conflict of interest.

\section{References}

[1] Eakins C, Ellis WD, Pruthi S et al. Second opinion interpretations by specialty radiologists at a pediatric hospital: rate of disagreement and clinical implications. Am J Roentgenol 2012; 199: 916-920
[2] Torok CM, Lee C, Nagy P et al. Neuroradiology second opinion consultation service: assessment of duplicative imaging. Am J Roentgenol 2013; 201: $1096-1100$

[3] Zan E, Yousem DM, Carone M et al. Second-opinion consultations in neuroradiology. Radiology 2010; 255: 135-141

[4] Haier J, Bergmann KO. Medicolegal aspects of tumor boards. Chirurg 2013; 84: $225-230$

[5] Dendl LM, Teufel A, Schleder S et al. Analysis of Radiological Case Presentations and their Impact on Therapy and Treatment Concepts in Internal Medicine. Rofo 2017; 189: 239-246 